\title{
SOME INDIVIDUAL AND SOCIAL FACTORS IN VENEREAL DISEASE : DISCUSSION
}

Dr. Hamilton Wilkie (the President) said he firmly believed that parental influence was one of the greatest factors deciding the future social behaviour of children. Many venereologists saw patients who blamed alcohol for their trouble, but he wondered if alcohol was not just a convenient excuse for lapse in behaviour. Statistics on the influence of alcohol were not reliable.

DR. T. E. OSMOND remarked on the fact that many of Dr. Sutherland's statistics were American. He himself had had a good deal of contact with the American authorities and American soldiers during the war, and he had come to the conclusion that the American soldier indulged in promiscuous sexual intercourse very much more frequently than did the British soldier. There was evidence for this statement in the fact that the American soldier required seven or eight times as many prophylactic packets as the British, so that possibly some of Dr. Sutherland's figures applied to the American citizen but not to the British.

He wanted also to mention the question of the relationship of sexual promiscuity to venereal disease. It used to be customary in farming communities for young men and women to walk out together, and it was customary for them to indulge in regular sexual intercourse; when a girl became pregnant the couple went to the parson and were married; but they did not get venereal disease.

Dr. HAMmond endorsed strongly Dr. Sutherland's remarks about the value of the social-medicine approach. They had tried such an approach in his clinic; every patient was invited to see the Sister outside clinic hours to discuss any social or marital problems, and it was surprising how many availed themselves of the opportunity, both men and women. The mere treatment of disease was by no means the only way, and perhaps not the most important, in which venereologists could serve their patients.

Dr. ANDrew said that Dr. Sutherland had shown the importance of social and economic factors in promiscuity and in the incidence of venereal disease, and he thought he might have led on to the obvious point that there was a higher incidence of promiscuity, or more specifically of venereal disease, among certain trades. He had noticed for some time that people in certain trades were prone to the acquisition of venereal disease : trades especially connected with transport (railway workers, sailors, gipsies). Rather more widely the problem was connected not so much with transport as with populations in movement. During the war one of the factors favouring the spread of venereal disease was the greater opportunity people had for making casual acquaintances, for having sexual intercourse without bearing responsibilities; this was especially true of men.

Dr. Sutherland made the point that venereal disease incidence was higher in workers in taverns and hotels and amongst people in similar trades, and he would suggest that once again the same population-movement was operative. He did not suggest that movement of population had anything to do with the fundamental problem, namely, why a man was promiscuous, or why one man was more promiscuous than another.

Dr. W. Neville Mascall wished to know if any statistics had been compiled regarding the question of promiscuity in relation to climatic conditions. He thought there was no doubt that people in the northern regions were quieter in their sexual habits than those in hot climates. He also thought that in countries where hot, spicy foods were the general rule the incidence of venereal disease was higher than in others,

Dr. McElligotT agreed that a high incidence of venereal disease was symptomatic of a still more important social sickress, caused by the breaking up of home life consequent on mobilization and, secondly, the movements of population inevitable in time of war.

Education was all-important, for in its earliest years something was put into a child which decided one way or another whether or not it would be promiscuous in later life. He agreed with Dr. Osmond that there was probably more promiscuity in the United States than in this country; he thought this was due more to racial differences than to climatic conditions. The large amount of American research work in this field suggested that the subject was worrying the medical profession in that country.

Dr. McElligott thought that, as both gonorrhœa and syphilis were more difficult to diagnose in women than in men, the capacity of a promiscuous female to spread infection was greater than that of an equally, or even more, promiscuous male.

Mr. A. J. KING said that Dr. Sutherland had given many interesting facts and figures, but he had often used the involved terminology of the psychiatrist. Was it necessary to put such relatively simple things into such complicated language? In effect Dr. Sutherland had said that stupid people, unhappy people, idle people, and people who drank too much were more liable to run into trouble than others, and all who worked in the subject of venereology would readily agree that this was true. One speaker had referred to the baneful effect of pornographic literature. Was it not the case that such a study as the Kinsey Report, from which Dr. Sutherland had quoted, might produce effects of this kind if it were too freely advertised to the lay public? When the speaker was last in the United States the Report had just been published and was then said to be third on the list of best sellers. This kind of literature might produce in the general public effects which were the reverse of those desired by the Central Council for Health Education.

DR. P. R. Oliver suggested that the research upon which Dr. Sutherland had given such an excellent report was a great waste of time. Did it matter whether those with venereal disease were more likely to come from 
the travelling class or the working class, the drinking class or the intellectuals? Could the intellectual be turned into the labourer, or the labourer into the intellectual ? Could people be stopped from travelling or going abroad? He suggested they could not. The Kinsey Report showed that promiscuity was frequent, and that was the world in which they were living. Nature was against a moral reform; nature had seen to it that man reached his sexual zenith approximately ten years before he reached the zenith of wisdom, and consequently no one could expect the rational man to govern the emotional.

There used to be two things that prevented promiscuity, or kept it at a low level: one was the fear of God, and the other was fear of disease. There were now peculiarly few people who allowed the fear of God to prevent them from doing anything, and the fear of disease was getting less and less.

Dr. Osmond had tried to assess the relative promiscuity of the American and British Armies by the number of prophylactic packets issued to each, but Dr. Oliver thought it probable that the higher number of prophylactic packets issued to American troops might be due rather to higher pay packets.

DR. MCDonald pointed out that Dr. Sutherland was perhaps the only speaker who had quoted figures; he had spoken of something which had happened and was found out. He had had to quote solely from American literature except for figures from work by, for example, Macfarlane of Newcastle. He thought they might be a little more humble when they realized that fact. Americans had read the Kinsey Report and now knew the problem in their own country, but we did not know it in ours.

He wondered whether Dr. Sutherland could give any figures about the success of Russian rehabilitation schemes. He had heard that work was being carried out and would be glad to know if there was any information about the result.

Dr. JEAN MORTON said that if parents shirked their duties there should be some proper form of teaching in the schools. One found when interviewing young girls and discussing their troubles that they had no standards of social behaviour.

DR. LAIRD agreed that much of the information presented by Dr. Sutherland consisted of statements made by patients, who might be boastful. He felt that, although it was true that British workers had not given these problems much attention, when one came to plan and consider the matter one reached the conclusion that it was not worth starting because the results would not be worth analysis.

Regarding promiscuity, which of course was the prime cause of the spread of venereal disease, the most important factor was the family unit. Where there was a proper family unit the family circumstances were right, and there was very little risk of children from such a family becoming promiscuous and suffering from venereal disease. He was interested in what Dr. Mascall said regarding climatic conditions. It was not his own impression that people in the far north were less promiscuous or suffered less from venereal disease than those in other parts of the country. However, he had recently added up the monthly figures of new cases in some of his clinics during the last three years; - and he was interested to find that in one clinic for three successive months there had not been a fresh case : these were the months of January, February, and March, 1947, when the ground had been covered with snow and ice and it was very uncomfortable to be out !

DR. R. R. WILlcox said that, while many people were apparently prepared to run down the Kinsey Report and even place it in the category of pornographic literature, there were few present who were unacquainted with it.

Regarding Dr. Osmond's comparison between the conduct of American and British soldiers, he considered that there was a tendency to be unjust to the Americans. It should not be forgotten that American soldiers had been thousands of miles away from their homes. Their conduct, therefore, should be compared with that of British troops in Hamburg and West Africa; and such a comparison would appreciably narrow the gap.

The psychiatric upsets of husbands during their wives' pregnancies was well known, and he would like to hear whether Dr. Sutherland proposed to set up antenatal clinics for expectant fathers.

DR. SutherLand (in reply) said that in his paper he had found himself handicapped because of the necessity of keeping to figures. This he found cramping and not particularly inspiring, but he had been obliged to do so if his contribution was to be of any value.

He thought venereal disease statistics were influenced more by individual and social factors than by climate. He doubted whether the question of food was a serious factor; it might have some effect upon the momentary stress and temptation but there were more fundamental points which determined whether that temptation was resisted or not.

Dr. McElligott had spoken of the effects of racial mixture; Dr. Sutherland thought that also was a cultural factor. Major Scott had spoken about degenerate literature. This was undoubtedly one factor in a complex situation. Modern man was being liberated from all his primary drives except that of sex; he was no longer hungry, he had social security, he was no longer cold, he was no longer lacking in protection from the elements, he was no longer exhausted by physical activity. The only primary drive that remained to create tension was the drive of sex. The only competitors to sex were the secondary drives. This brought him again to the question of culture. A suggestion was made that he (Dr. Sutherland) was a little too psychological. He did not see how one could examine man and the forces at work upon him without taking account of psychological factors. It would be an equally unreasonable criticism to say that someone was too physiological.

Mr. KING : It was the terminology I objected to.

DR. SuTHERLAND said that it was difficult not to use technical terminology. He was not defending himself, he was attempting to seek the truth. He was not himself a psychologist ; but were they not all too suspicious of the psychiatrist's language just because it was technical? Surely all techniques must have a terminology which was precise. The psychiatrists were building up a science which was increasingly scientific; and his feeling was that it was very important that those who had been concerned more with physical medicine should study the discoveries being made in psychological medicine and even adopt some of the terminology in order to give precision to the expression of their views.

Although it suffered from being based on interview rather than on observation, the Kinsey Report seemed to him to be a useful study of the habits of people. In 
the past we had been too much concerned with studying the natural history of disease : the great advances in medicine in the future would be made from the study of the natural history of man. When man became diseased the disease was only an expression (he was becoming psychological in his terminology) of his individual reaction to an external stimulus.

Turning to the speaker who had described the Kinsey investigation as a waste of time and who had contended that the world must be made safe for promiscuity, he asked how they could know whether they should make the world safe for promiscuity or not until they had studied the true nature and needs of man. It was not enough to have impressions. Admittedly, the Kinsey report was not as decisively objective as desirable, because it was based upon statements and not upon observation of behaviour; perhaps that would come, although in this field it would be a little difficult !

It had been objected that his figures were too much from American sources. He could only say that he had searched the literature impartially for the information he sought.

He did not know the results of the Russian atlempts at rehabilitation. He had seen some work which suggested that they were good, but it was difficult to tell what was happening in Russia. It did appear, however, that some extremely interesting experiments in the matter of rehabilitation were being carried out, and some promising claims had been made for the results.

He welcomed the suggestion that health education should be started in schools. This question of education to make good in the schools the deficiencies of the training and culture of the child in the home was a vital one, and one to which he was glad to say educationists were already giving more and more attention. There was a movement in all directions towards attempting to find out the nature and needs of the child and to meet those needs. The leaders in the educational profession were undoubtedly reorientating themselves and thinking in terms of personality and character development rather than merely of passing across pre-digested information in the hope that at the proper moment it would be regurgitated relatively unchanged.

Dr. Laird had said that many of the statements he had made were not facts. If he had said " some of the statements" Dr. Sutherland would have agreed; but the statements he had made about broken homes, conflicts in the homes, assistance sought from other organizations, intelligence, records of delinquency, records of people who had been in the courts, and the educational background were facts. He was attempting to find a statistical basis for his observations. Admittedly, the observations upon which the statistics were based might have been at fault, but one must have this information and if it was felt that the American information was not reliable then they must find out for themselves what the position was here.

One of the promising things which was happening in medicine as a whole was a movement towards social medicine-a looking beyond the presenting symptom to the individual as a whole and his life history; and he hoped that this movement would gain in strength.

The fundamental problem was one of changing culture. One of the speakers had spoken about the part played by the movement of population. He entirely agreed; but this movement of population was merely a phase of culture. They were going through an extremely demoralizing phase of technical advance; no one in the room still held the firm and secure convictions he had as a child. It was interesting to meet people of eighty who were raised in the Victorian age. They found everything black and white, they knew exactly where they stood. But the individual who grew up in a changing culture found when he moved out from home and school that much he had been taught was neither believed nor practised in the community as a whole. There arose a conflict between the moral training he had received and what was going on around him. Dr. Sutherland believed that the major factor in the breakdown in morality at the present time was that, in the whole of life-religion, education, medicine, industry, politics-society was passing from an authoritarian regime to a democratic regime, from a complacent accepting attitude to an iconoclastic, questioning, critical attitude. When people had grown to adolescence, they were no longer content to continue to believe and practise the things that they had been told they must unquestioningly believe and practise just because those in authority above them had said they must. The difficulty was that external, arbitrary discipline had not been generally replaced by an internal discipline based upon a rational examination of the facts. We had to see that the relevant facts were discovered and made known to all concerned: only the individual himself could see that they were applied to his way of life. 